\title{
Synthesis and low-temperature dehydrating imidation polymerization of 1,4-dihydro-1,4- diarsininetetracarboxylic acid dianhydride
}

\author{
Kensuke Naka $^{1,2}$, Manabu Arita ${ }^{1,2}$, Tatsuo Shimamoto ${ }^{1,2}$, Yasuhiro Morisaki ${ }^{1,2}$ and Yoshiki Chujo ${ }^{1,2}$ \\ cis-1,4-Dihydro-1,4-dimethyl-1,4-diarsinine-2,3,5,6-tetracarboxylic acid dianhydride (cis-DHDADA) was quantitatively formed from cis- \\ 1,4-dihydro-1,4-dimethyl-2,3,5,6-tetrakis(t-butoxycarbonyl)-1,4-diarsinine (cis-DHDAtBu) treated with formic acid as a Brønsted acid \\ or with a cationic gold $(\mathrm{I})$ catalyst as a Lewis acid. X-ray crystallography suggested that the six-membered ring in cis-DHDADA is in a \\ boat conformation and is nearly flat, with the $\mathrm{As}-\mathrm{C}=\mathrm{C}$ bond angle of cis-DHDADA extending to $133^{\circ}$. The ultraviolet-visible absorption \\ spectra of cis-DHDADA in $\mathrm{CH}_{2} \mathrm{Cl}_{2}$ showed a long-wavelength absorption maximum at $321 \mathrm{~nm}$, which was redshifted compared with \\ that of cis-DHDAtBu. Polymerization of cis-DHDADA with 1,3-bis(4-aminophenoxy)benzene at $80{ }^{\circ} \mathrm{C}$ in $\mathrm{N}, \mathrm{N}$-dimethylacetoamide \\ (DMAc) for $12 \mathrm{~h}$ yielded a soluble polyimide, with number-average and weight-average molecular weights estimated at 23400 \\ and 60300 , respectively. The polyimide was obtained even when the polymerization was conducted at $60{ }^{\circ} \mathrm{C}$ for $24 \mathrm{~h}$. \\ Polymer Journal (2011) 43, 358-363; doi:10.1038/pj.2010.148; published online 9 February 2011
}

Keywords: 1,4-diarsa-2,5-cyclohexadiene; dehydrating imidation polymerization; organoarsenic compounds; polyimide; soluble polyimide

\section{INTRODUCTION}

The incorporation of metallic or metalloid elements, such as S, Se, PR, $\mathrm{SiR}_{2}, \mathrm{GeR}_{2}$ and $\mathrm{BR}$, into polymer main chains appears to be a promising way of producing materials with useful properties. ${ }^{1-5}$ For example, heteroatom-containing poly(phenylene)s, such as poly(phenyleneoxide), poly(phenylenesulfide) and polyaniline, are industrially important as engineering plastics and electrical materials. Heteroaromatic polymers, such as polythiophene and polypyrrole, have also been intensively investigated and widely applied. Among the various types of such polymers, much attention has been paid to heteroatomcontaining polyimides in attempts to develop high-performance functional polymers, such as high-refractive-index polymers for optical applications, polymers resistant to atomic oxygen and ultraviolet radiation, as well as thermostable polymers. ${ }^{6-10}$

Organoarsenic compounds are currently being considered as ligands for transition metals because of their special properties; ${ }^{11,12}$ however, fewer studies have been conducted with these than with their phosphorus analogs, because most organoarsenic compounds are prepared from arsenic chlorides or arsenic hydrides and require extreme caution in handling because of their volatility and toxicity. We previously reported the facile synthesis of a novel cis-1,4-diarsa2,5-cyclohexadiene, that is, cis-1,4-dihydro-1,4-dimethyl-2,3,5,6tetrakis( $t$-butoxycarbonyl)-1,4-diarsinine (cis-DHDAtBu), which was synthesized by the radical reaction of pentamethylcyclopentaarsine
(cyclo-(MeAs) $)_{5}$ and di-t-butyl acetylenedicarboxylate. ${ }^{13,14}$ Their stability against air and moisture was high enough to allow handling in air. In this study, we found that cis-1,4-dihydro-1,4-dimethyl-1,4diarsinine-2,3,5,6-tetracarboxylic acid dianhydride (cis-DHDADA) was quantitatively formed from cis-DHDAtBu treated with formic acid as a Brønsted acid. We also found that dehydrating imidation polymerization of cis-DHDADA with diamines proceeded in a solution without catalysts even at $60^{\circ} \mathrm{C}$. This fact stands in sharp contrast to the synthesis of most polyimides that are processed in the form of their poly(amic acid) precursors and then thermally or chemically converted to imide structures. It should also be noted that this is the first reported polyimide containing arsenic atoms in the main chain.

\section{EXPERIMENTAL PROCEDURE}

Materials

Unless otherwise noted, all reagents and chemicals were purchased from commercial sources and used without further purification. cis-DHDAtBu was synthesized as described in our previous report. ${ }^{14}$ Gold(I) chloride and silver(I) trifluoromethanesulfonate were obtained from Sigma-Aldrich Chemical Co. (St Louis, MO, USA).

\section{Measurements}

${ }^{1} \mathrm{H}(300 \mathrm{MHz})$ and ${ }^{13} \mathrm{C}(100 \mathrm{MHz})$ nuclear magnetic resonance (NMR) spectra were recorded on a Bruker PDX-300 spectrometer (Bruker, Karlsruhe, Germany): the samples were analyzed in $\mathrm{CDCl}_{3}$ or dimethyl sulfoxide- $\mathrm{d}_{6}$

${ }^{1}$ Department of Chemistry and Materials Technology, Graduate School of Science and Technology, Kyoto Institute of Technology, Kyoto, Japan and ${ }^{2}$ Department of Polymer Chemistry, Graduate School of Engineering Kyoto University, Kyoto, Japan

Correspondence: Professor K Naka, Department of Chemistry and Materials Technology, Graduate School of Science and Technology, Kyoto Institute of Technology, Goshokaidocho, Matsugasaki, Sakyo-ku, Kyoto 606-8585, Japan.

E-mail: naka@chem.kit.ac.jp

Received 1 November 2010; revised 6 December 2010; accepted 7 December 2010; published online 9 February 2011 
(DMSO- $\mathrm{d}_{6}$ ) using tetramethylsilane as an internal standard. Ultravioletvisible spectra were obtained on a SHIMADZU UV-3600 spectrophotometer (Shimadzu, Kyoto, Japan) from samples in $\mathrm{CH}_{2} \mathrm{Cl}_{2}$ at room temperature. Elemental analyses were performed at the Microanalytical Center of Kyoto University. High-resolution mass spectra were obtained on a JEOL JMS700 spectrometer (JEOL, Tokyo, Japan). Gel permeation chromatography was performed on a TOSOH 8020 (TSK-gel $\alpha-\mathrm{M}$ column) (Tosoh, Tokyo, Japan) using a $N, N$-dimethyformamide (DMF) solution containing $10-\mathrm{mM} \mathrm{LiBr}$ as an eluent after calibration with standard polystyrene. Fourier-transforminfrared (FT-IR) spectra were obtained on a Perkin Elmer 2000 spectrometer (PerkinElmer, Waltham, MA, USA). All procedures except annealing the polyimide were performed under nitrogen or argon atmospheres.

\section{$\mathrm{X}$-ray crystal structure analysis}

X-ray diffraction patterns were collected on a Rigaku R-AXIS RAPID-F (Rigaku, Akishima, Japan) graphite-monochromated Mo K $\alpha(\lambda=0.71075 \AA)$ radiation diffractometer with an imaging plate. A symmetry-related absorption correction was carried out using the program ABSCOR..$^{15}$ The structures were solved by means of Patterson methods (Dirdif $99.2^{16}$ and refined $\left(\right.$ SHELXL-97 ${ }^{17}$ ) using Yadokari-XG. ${ }^{18}$ The Oak Ridge Thermal Ellipsoid Plot (ORTEP)-III ${ }^{19}$ program was used to generate the X-ray structural diagrams.

\section{cis-DHDADA}

Method 1. cis-DHDAtBu $(2.2 \mathrm{~g}, 3.4 \mathrm{mmol})$ was dissolved in formic acid $(500 \mathrm{ml})$ and stirred at $120^{\circ} \mathrm{C}$ for $24 \mathrm{~h}$. The volatile components were removed under reduced pressure to yield a yellow residue. After the residue was extracted with $\mathrm{CHCl}_{3}$ to yield a yellow solution, the solvent was removed to result in a yellow solid (yield: 93\%).

Method 2. cis-DHDAtBu ( $270 \mathrm{mg})$ was added to a mixture of gold(I) chloride $(9.0 \mathrm{mg}, \quad 0.039 \mathrm{mmol})$ and silver(I) trifluoromethanesulfonate $(10.0 \mathrm{mg}$, $0.039 \mathrm{mmol})$ in toluene $(20.0 \mathrm{ml})$. After the mixture was stirred at $80^{\circ} \mathrm{C}$ for $16 \mathrm{~h}$, residual gold and silver were filtered out with a silica gel to result in a yellow solution. The solvent was removed to yield a yellow solid (yield: $85 \%$ ).

FT-IR ( $\mathrm{KBr}$ disk) at $\mathrm{cm}^{-1}$ : 1830, $1800(\mathrm{C}=\mathrm{O})$ and $1240(\mathrm{C}-\mathrm{O}) .{ }^{1} \mathrm{H}-\mathrm{NMR}$ $\left(300 \mathrm{MHz}, \mathrm{CDCl}_{3}\right): \delta 1.81(6 \mathrm{H}, \mathrm{s}) .{ }^{13} \mathrm{C}-\mathrm{NMR}\left(100 \mathrm{MHz}, \mathrm{CDCl}_{3}\right): \delta 162.99$, 152.77 and 10.09. HR FAB-mass spectra $(\mathrm{m} / \mathrm{z})$ : calculated for $\mathrm{C}_{10} \mathrm{H}_{6} \mathrm{O}_{6} \mathrm{As}_{2}$ and 371.8596; found, 372.8684. Anal. calculated for $\mathrm{C}_{10} \mathrm{H}_{6} \mathrm{O}_{6} \mathrm{As}_{2}, \mathrm{C}, 32.29$; and $\mathrm{H}$, 1.63. Found: C, 32.03; and $\mathrm{H}, 1.55$.

Polymerization. A typical polymerization procedure was as follows: a mixture of cis-DHDADA (50 mg, $0.13 \mathrm{mmol}$ ) and 1,3-bis(4-aminophenoxy)benzene (BAB; $39 \mathrm{mg}, 0.13 \mathrm{mmol})$ in $N, N$-dimethylacetoamide (DMAc) $(0.5 \mathrm{ml})$ was stirred at $80^{\circ} \mathrm{C}$ for $12 \mathrm{~h}$ to yield a yellow solution. The solution was added to methanol to result in a yellow precipitate.

PI-1: 51\% yield, FT-IR ( $\mathrm{KBr}$ disk) at $\mathrm{cm}^{-1}: 1760,1703(\mathrm{C}=\mathrm{O})$ and 1382 (C-N). ${ }^{1} \mathrm{H}-\mathrm{NMR}(300 \mathrm{MHz}$, DMSO-d 6 ): $\delta 7.42(\mathrm{~d}, 4 \mathrm{H}), 7.18(\mathrm{~d}, 4 \mathrm{H}), 7.87-$ $6.75(\mathrm{~m}, 4 \mathrm{H})$ and $1.63(\mathrm{~s}, 3 \mathrm{H}) .{ }^{13} \mathrm{C}-\mathrm{NMR}\left(100 \mathrm{MHz}, \mathrm{DMSO}-\mathrm{d}_{6}\right): \delta 169.16$, $158.17,156.03,149.43,131.85,128.78,127.49,119.49,114.42,109.94$ and 10.80 .

PI-2: 57\% yield, FT-IR (KBr disk) at $\mathrm{cm}^{-1}: 1760,1695(\mathrm{C}=\mathrm{O})$ and $1386(\mathrm{C}-$ N). ${ }^{1} \mathrm{H}-\mathrm{NMR}\left(300 \mathrm{MHz}, \mathrm{CDCl}_{3}\right): \delta 7.38(\mathrm{~d}, 2 \mathrm{H}), 7.15(\mathrm{~d}, 2 \mathrm{H})$ and $1.81(\mathrm{~s}, 3 \mathrm{H})$. ${ }^{13} \mathrm{C}-\mathrm{NMR}\left(100 \mathrm{MHz}, \mathrm{CDCl}_{3}\right): \delta 168.57,156.29,149.93,127.37,126.78,119.58$ and 10.90 .

\section{RESULTS AND DISCUSSION}

\section{Synthesis of cis-DHDADA}

We found that cis-DHDADA was quantitatively formed from cis-DHDAtBu treated with formic acid as a Brønsted acid. When cis-DHDAt $\mathrm{Bu}$ was dissolved in formic acid and stirred at $120^{\circ} \mathrm{C}$, the reaction mixture turned yellow within $5 \mathrm{~min}$. After the removal of formic acid under reduced pressure and extraction with $\mathrm{CHCl}_{3}$, the solvent was removed to yield a yellow solid. In the FT-IR spectrum, the product showed characteristic $\mathrm{C}=\mathrm{O}$ vibrations at 1830 and $1800 \mathrm{~cm}^{-1}$, indicating the formation of an anhydride structure. The ${ }^{1} \mathrm{H}$ - and ${ }^{13} \mathrm{C}-\mathrm{NMR}$, FAB-MASS spectrometry and elemental

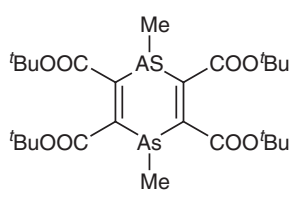

cis-DHDAtBu

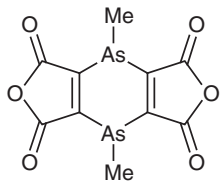

cis-DHDADA
Scheme 1 Synthesis of cis-DHDADA from cis-DHDAtBu.

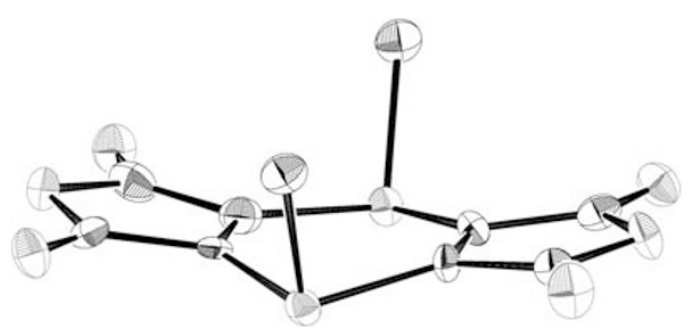

Figure 1 ORTEP drawing of cis-1,4-dihydro-1,4-dimethyl-1,4-diarsinine2,3,5,6-tetracarboxylic acid dianhydride with thermal ellipsoids shown at the $50 \%$ probability level. The hydrogen atoms are omitted for clarity.

analysis data all supported the formation of cis-DHDADA. Although $t$-butyl esters are known to be readily cleaved by moderately acidic hydrolysis, the anhydride structure was obtained in the present case (Scheme 1).

The same cis-DHDADA was also obtained from cis-DHDAtBu using the cationic gold(I) catalyst as a Lewis acid, which was prepared in situ from gold(I) chloride and silver(I) trifluoromethanesulfonate. The structure of cis-DHDADA was estimated from the FT-IR, ${ }^{1} \mathrm{H}$ - and ${ }^{13} \mathrm{C}$ NMR, and FAB-MASS spectrometry results. The gold(I) catalyst may interact not only with the carbonyl but also with the arsenic groups of cis-DHDAtBu to reduce electrons near the carbonyl carbons. cisDHDADA was simply purified by filtering out residual gold and silver. cis-1,4-Dihydro-1,4-dimethyl-2,3,5,6-tetrakis(methoxycarbonyl)1,4-diarsinine, the methyl ester analog of cis-DHDAt $\mathrm{Bu}$, hardly reacted when Brønsted acid was used to obtain cis-DHDADA, because the methoxy group has fewer electrons than the $t$-butoxy group. cisDHDADA, however, was obtained from cis-1,4-dihydro-1,4-dimethyl2,3,5,6-tetrakis(methoxycarbonyl)-1,4-diarsinine using the cationic gold(I) catalyst.

The stereochemical structure of cis-DHDADA in the crystal form was determined by X-ray crystallography. The crystallographic data suggest that the six-membered ring was in a boat conformation and was nearly flat (Figure 1). A selection of bond lengths and angles for the crystals is summarized in Tables 1 and 2. Although the usual bond angle at the $\mathrm{sp}^{2}$-hybridized carbon is $120^{\circ}$ and the As- $\mathrm{C}=\mathrm{C}$ bond angle of cis-DHDAtBu was $121^{\circ}$, 14 that of cis-DHDADA extended to $133^{\circ}$. In our previous report, the $\mathrm{As}-\mathrm{C}=\mathrm{C}$ bond angle of the chair conformer of trans-DHDAtBu extended to $129^{\circ} .{ }^{\circ}$ In a similar phosphorus compound, the $\mathrm{P}-\mathrm{C}=\mathrm{C}$ angles extend to only $122^{\circ} .{ }^{20}$ The flexibility of the bond angles around the arsenic center is an inherent property in the organoarsenic compounds. The average As-C bond length was $1.939 \AA$, which was shorter than that of $c i s$-DHDAtBu $(1.971 \AA)$. This indicates an increase in the $\pi$-bonding character of the As- $\mathrm{C}$ bonds in the six-membered ring. The interior angles around the arsenic atoms of the six-membered ring were reduced (to $93.2^{\circ}$ ) compared with those in cis-DHDAtBu (at $95.0^{\circ}$ ). The repulsion of the paired electrons around the arsenic atoms may have decreased because of their delocalization in the six-membered ring. 
Table 1 Selected crystallographic data and refinement parameters

\begin{tabular}{|c|c|}
\hline & cis-DHDADA \\
\hline Empirical formula & $\mathrm{C}_{10} \mathrm{H}_{6} \mathrm{As}_{2} \mathrm{O}_{6}$ \\
\hline Formula weight & 371.99 \\
\hline Crystal system & Monoclinic \\
\hline Space group & $P 21$ \\
\hline$a(\AA)$ & $7.379(4)$ \\
\hline$b(\AA)$ & $7.971(4)$ \\
\hline$c(\AA)$ & $10.272(5)$ \\
\hline$\alpha(\mathrm{deg})$ & 90 \\
\hline$\beta$ (deg) & $103.55(3)$ \\
\hline$\gamma(\mathrm{deg})$ & 90 \\
\hline$V\left(\AA^{3}\right)$ & $587.3(5)$ \\
\hline Z & 2 \\
\hline$D_{\text {calcd }}\left(\mathrm{g} \mathrm{cm}^{-3}\right)$ & 2.103 \\
\hline$\mu\left(\mathrm{mm}^{-1}\right)$ & 5.705 \\
\hline$T(\mathrm{~K})$ & 116 \\
\hline Reflections collected & 5111 \\
\hline Independent reflections $\left(R_{\text {int }}\right)$ & $2494(0.0840)$ \\
\hline Observed reflections $(I>2 \sigma(I))$ & 1805 \\
\hline Parameters & 165 \\
\hline$T_{\max } / T_{\min }$ & $0.5993 / 0.5993$ \\
\hline Residual density $\left(e \AA^{-3}\right)$ & $0.874 /-0.697$ \\
\hline$R_{1}$ & 0.0573 \\
\hline$w R_{2}$ & 0.1337 \\
\hline GooF & 0.974 \\
\hline
\end{tabular}

Abbreviation: cis-DHDADA, cis-1,4-dihydro-1,4-dimethyl-1,4-diarsinine-2,3,5,6-tetracarboxylic acid dianhydride; GooF, goodness of fit.

Table 2 Selected distances $(\AA)$ and angles (deg) of cis-DHDADA

\begin{tabular}{lccc}
\hline $\operatorname{As}(1)-\mathrm{As}(2)$ & $3.961(2)$ & & \\
$\mathrm{C}(9)-\mathrm{C}(16)$ & $1.347(15)$ & $\mathrm{R}$ & $1.324(16)$ \\
$\mathrm{As}(1)-\mathrm{C}(9)$ & $1.932(11)$ & $\mathrm{As}(2)-\mathrm{C}(16)$ & $1.936(12)$ \\
$\mathrm{As}(1)-\mathrm{C}(14)$ & $1.937(12)$ & $\mathrm{As}(2)-\mathrm{C}(11)$ & $1.950(12)$ \\
$\mathrm{C}(9)-\mathrm{As}(1)-\mathrm{C}(14)$ & $93.5(4)$ & $\mathrm{C}(16)-\mathrm{As}(2)-\mathrm{C}(11)$ & $92.9(5)$ \\
$\mathrm{C}(16)-\mathrm{C}(9)-\mathrm{As}(1)$ & $131.5(8)$ & $\mathrm{C}(14)-\mathrm{C}(11)-\mathrm{As}(2)$ & $132.3(9)$ \\
$\mathrm{C}(11)-\mathrm{C}(14)-\mathrm{As}(1)$ & $133.2(9)$ & $\mathrm{C}(9)-\mathrm{C}(16)-\mathrm{As}(2)$ & $133.6(8)$ \\
$\mathrm{C}(14)-\mathrm{C}(11)-\mathrm{C}(12)$ & $106.4(11)$ & $\mathrm{C}(11)-\mathrm{C}(14)-\mathrm{C}(10)$ & $109.1(11)$ \\
$\mathrm{C}(9)-\mathrm{C}(16)-\mathrm{C}(18)$ & $107.5(10)$ & $\mathrm{C}(16)-\mathrm{C}(9)-\mathrm{C}(17)$ & $107.6(10)$ \\
\hline
\end{tabular}

Abbreviation: cis-DHDADA, cis-1,4-dihydro-1,4-dimethyl-1,4-diarsinine-2,3,5,6-tetracarboxylic acid dianhydride.

The ultraviolet-visible absorption spectra of cis-DHDADA in $\mathrm{CH}_{2} \mathrm{Cl}_{2}$ showed a long-wavelength absorption maximum at $321 \mathrm{~nm}$ $\left(6400 \mathrm{M}^{-1} \mathrm{~cm}^{-1}\right)$, which was redshifted compared with that of cisDHDAtBu at $272 \mathrm{~nm}\left(11000 \mathrm{M}^{-1} \mathrm{~cm}^{-1}\right)$ (Figure 2). The conjugation system of the nearly flat six-membered ring of cis-DHDADA affected the absorption. When cis-DHDAtBu was dissolved in formic acid and stirred at $120^{\circ} \mathrm{C}$, the reaction mixture turned yellow within $5 \mathrm{~min}$, as described above. This indicates that cis-DHDADA was formed in the solution. The conjugation stabilization might be the main reason for the facile formation of the dianhydride structure.

\section{Polymerization}

The polymerization of cis-DHDADA with $\mathrm{BAB}$ was conducted at $80^{\circ} \mathrm{C}$ in DMAc for $12 \mathrm{~h}$ (Scheme 2). The polymerization proceeded in a homogeneous solution, which was subsequently added to methanol to yield a yellow precipitate. The obtained polymer (PI-1) was soluble in organic solvents, including DMAc, DMF and

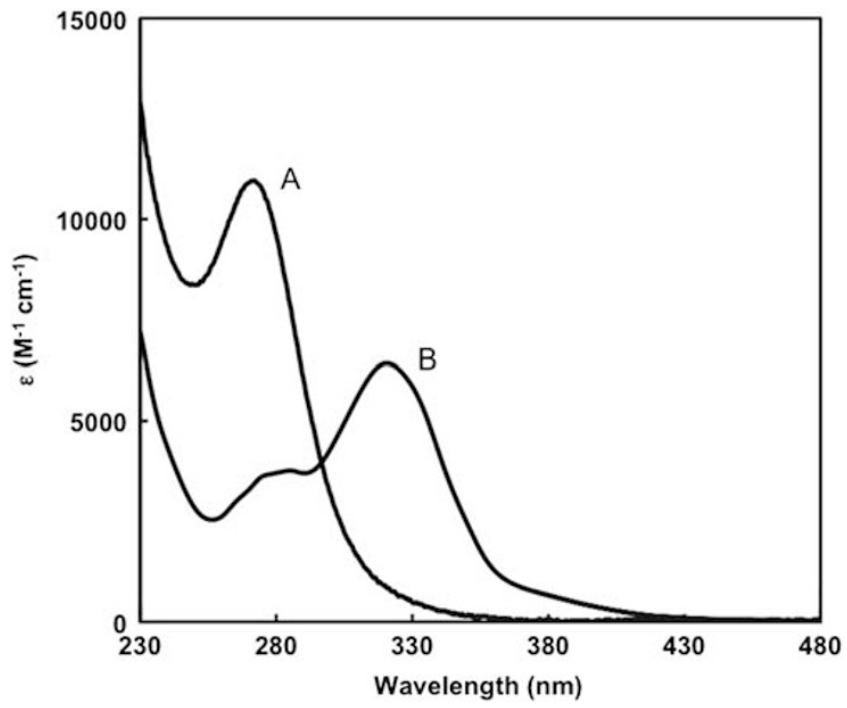

Figure 2 Ultraviolet-visible absorption spectra of cis-1,4-dihydro-1,4dimethyl-2,3,5,6-tetrakis(t-butoxycarbonyl)-1,4-diarsinine (A) and cis-1,4dihydro-1,4-dimethyl-1,4-diarsinine-2,3,5,6-tetracarboxylic acid dianhydride (B) in $\mathrm{CH}_{2} \mathrm{Cl}_{2}$.

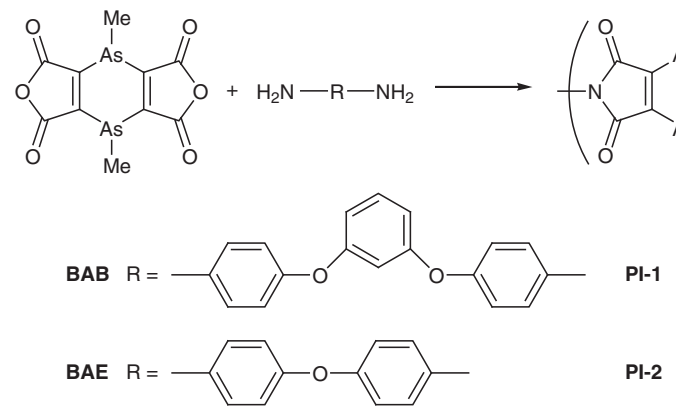

Scheme 2 Polymerization of cis-DHDADA with BAB or BAE.

DMSO, and partially soluble in $\mathrm{CHCl}_{3}, \mathrm{CH}_{2} \mathrm{Cl}_{2}, \mathrm{CH}_{3} \mathrm{CN}$ and tetrahydrofuran (THF). From gel permeation chromatography analysis (DMF $0.1 \mathrm{~mm} \mathrm{LiBr,} \mathrm{PSt} \mathrm{standards),} \mathrm{the} \mathrm{number-average} \mathrm{and} \mathrm{weight-}$ average molecular weights of PI-1 were estimated to be 23400 and 60300 , respectively. The obtained polymer was identified by FT-IR and NMR. The FT-IR analysis showed peaks unique to the imide structure at $1373 \mathrm{~cm}^{-1}\left(\mathrm{C}-\mathrm{N}\right.$ stretching) and at 1715 and $1760 \mathrm{~cm}^{-1}$ ( $\mathrm{C}=\mathrm{O}$ stretching). The NMR spectra are in agreement with the proposed structure. The ${ }^{1} \mathrm{H}-\mathrm{NMR}$ spectrum showed one sharp resonance for As-Me at 1.64 p.p.m., which was shifted downfield compared with that of cis-DHDADA (Figure 3a). The peak-area ratio of the aromatic (6.7-7.5 p.p.m.) and methyl moieties confirmed the polyimide structure. Analysis of PI- 1 by ${ }^{13} \mathrm{C}-\mathrm{NMR}$ spectroscopy in DMSO- $\mathrm{d}_{6}$ showed only one sharp resonance for the methyl carbon at 10.8 p.p.m., suggesting that the arsenic in the polymer existed in a pure form and no oxidized arsenic was present (Figure $3 \mathrm{~b}$ ). The polyimide showed a $10 \%$ weight loss at $329^{\circ} \mathrm{C}$ under air.

The polymerization of cis-DHDADA with bis( $p$-aminophenyl) ether was conducted at $90^{\circ} \mathrm{C}$ in DMAc for $12 \mathrm{~h}$ (Scheme 2). The solution was added to methanol to yield a yellow precipitate. The obtained polymer (PI-2) was partially soluble in DMSO and DMF, and insoluble in $\mathrm{CHCl}_{3}, \mathrm{CH}_{2} \mathrm{Cl}_{2}, \mathrm{CH}_{3} \mathrm{CN}$ and THF. 
a

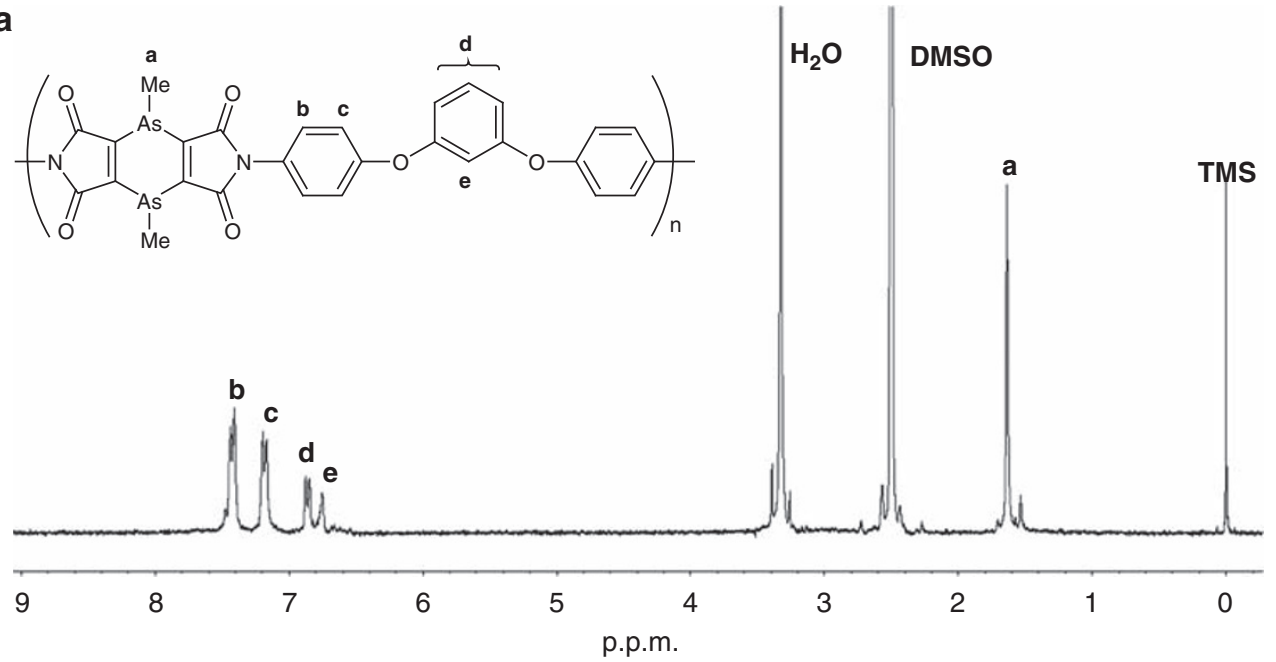

b

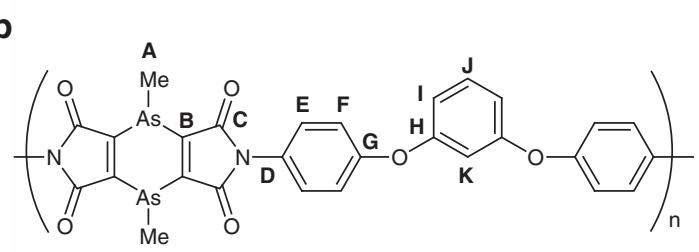

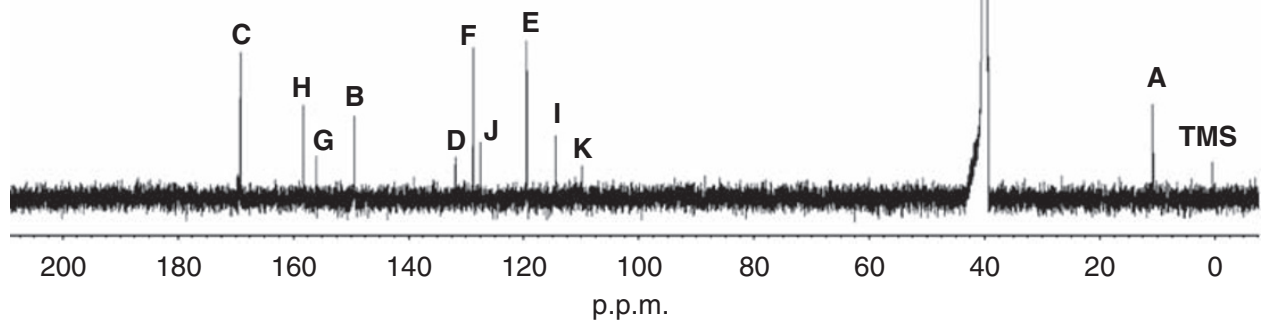

Figure 3 (a) ${ }^{1} \mathrm{H}$ - and (b) ${ }^{13} \mathrm{C}$-nuclear magnetic resonance spectra of $\mathrm{PI}-1$ in DMSO- $\mathrm{d}_{6}$.

From a gel permeation chromatography analysis (DMF $0.1 \mathrm{~mm} \mathrm{LiBr}$, PSt standards), the number-average and weight-average molecular weights of the soluble part of PI-2 were estimated to be 5800 and 11300 , respectively. The FT-IR analysis showed peaks unique to the imide structure at $1382 \mathrm{~cm}^{-1}$ (C-N stretching), 1703 and $1760 \mathrm{~cm}^{-1}$ ( $\mathrm{C}=\mathrm{O}$ stretching). A soluble part of PI-2 in DMSO was identified by ${ }^{1} \mathrm{H}-\mathrm{NMR}$, which is in agreement with the proposed structure. The ${ }^{1} \mathrm{H}-\mathrm{NMR}$ spectrum showed one sharp resonance for As-Me at 1.66 p.p.m.

The polymerization of cis-DHDADA with $\mathrm{BAB}$ was conducted at $60{ }^{\circ} \mathrm{C}$ in DMAc for $12 \mathrm{~h}$. The ${ }^{1} \mathrm{H}-\mathrm{NMR}$ and FT-IR analyses indicated that the polymer structure was a mixture of the imide and amide acid units. In addition to the As-Me resonance for the imide unit, two sets of As-Me signals corresponding to the amide acid were observed. The amide acid has two isomeric structures, that is, the meta- and para-isomers. The peaks corresponding to meta- and para-isomeric structures can be separated. For the para-isomer, the chemical shift of As-Me should appear as a singlet peak. Conversely, for the meta-isomer, two peaks assigned to As-Me in different chemical environments should be expected. The ${ }^{1} \mathrm{H}-\mathrm{NMR}$ spectrum at the methyl region shows the peaks corresponding to the meta- and paraisomers of the amide acid unit and the imide unit (Figure 4).
We conducted the polymerizations at different temperatures and at different times. The results are summarized in Table 3 . The polyimide was obtained even when the polymerization was conducted at $60^{\circ} \mathrm{C}$ for $24 \mathrm{~h}$ and the molecular weight increased with an increase in the polymerization time to $48 \mathrm{~h}$. The polyimide structure was also formed at room temperature. However, the ratio of the imide unit against the amide acid unit was not improved even when the polymerization was conducted at room temperature for $96 \mathrm{~h}$. The solubility of the polymer decreased when both reaction temperature and time were increased (Scheme 3).

\section{CONCLUSIONS}

We found that cis-DHDADA was quantitatively formed from cis-DHDAtBu when treated with formic acid as a Brønsted acid or the cationic gold(I) catalyst as a Lewis acid. The X-ray crystallography suggested that the six-membered ring in cis-DHDADA is in a nearly flat boat conformation and that the As $-\mathrm{C}=\mathrm{C}$ bond angle of cis-DHDADA extends to $133^{\circ}$. The ultraviolet-visible absorption spectra of cis-DHDADA in $\mathrm{CH}_{2} \mathrm{Cl}_{2}$ showed a long-wavelength absorption maximum at $321 \mathrm{~nm}$, which was redshifted compared with that of cis-DHDAtBu. The conjugation stabilization may be the main reason for the formation of the dianhydride structure. 
a1 a2

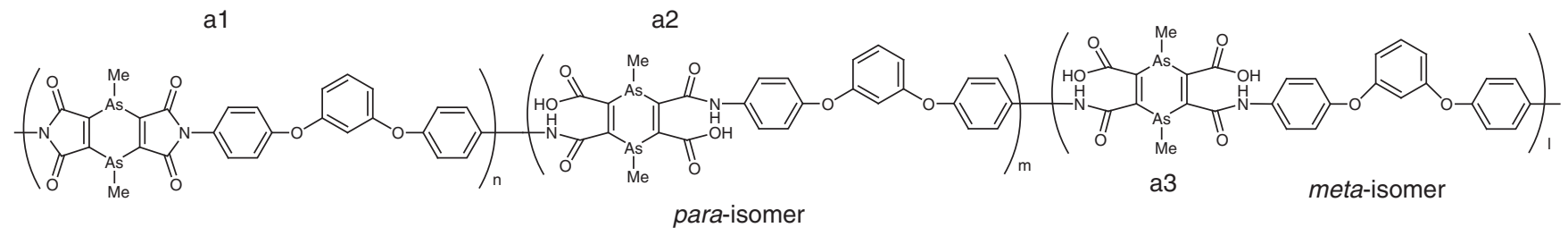

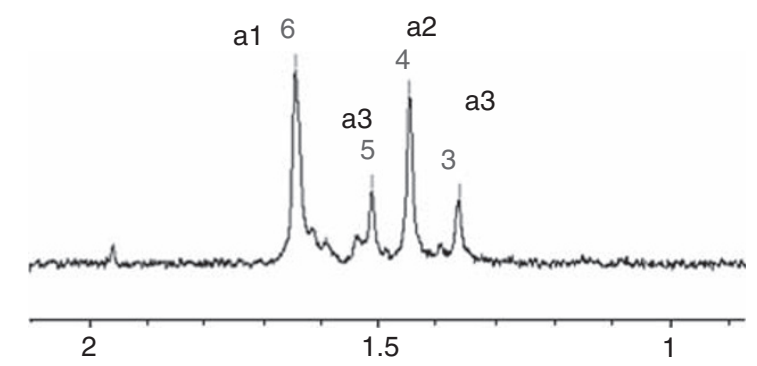

Figure 4 The aliphatic region of the ${ }^{1} \mathrm{H}$-nuclear magnetic resonance spectrum of the polymer obtained from the polymerization of cis-1,4-dihydro-1,4dimethyl-1,4-diarsinine-2,3,5,6-tetracarboxylic acid dianhydride with 1,3-bis(4-aminophenoxy)benzene conducted at $60^{\circ} \mathrm{C}$ in DMAc for $12 \mathrm{~h}$ (run 3 in Table 2 ).

Table 3 Results of polymerization

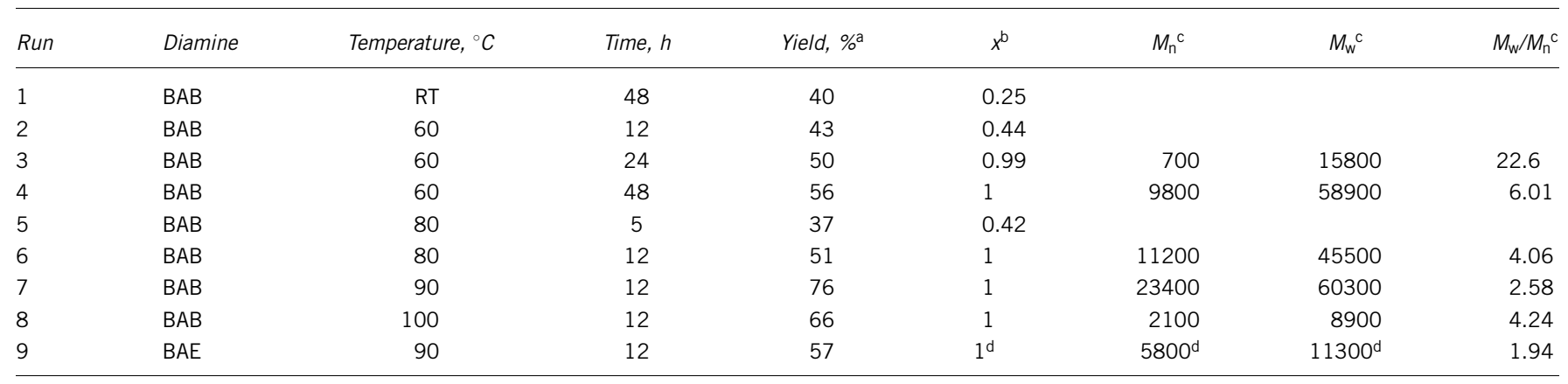

Abbreviations: BAB, 1,3-bis(4-aminophenoxy)benzene; BAE, bis( $p$-aminophenyl) ether; GPC, gel permeation chromatography; NMR, nuclear magnetic resonance; RT, room temperature. alsolated yield after reprecipitation into $\mathrm{CHCl}_{3}$.

bB ${ }^{1} \mathrm{H}-\mathrm{NMR}$.

'By GPC (10 mm LiBr in DMF). Polystyrene standard.

dDMF soluble part.

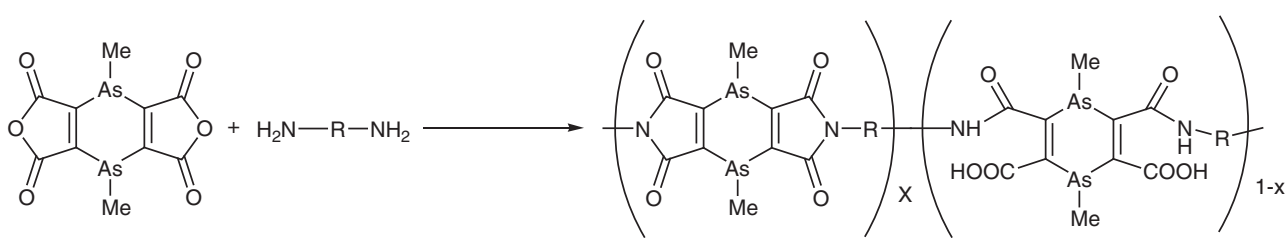<smiles>Cc1ccc(Oc2cccc(Oc3ccc(C)cc3)c2)cc1</smiles>

Scheme 3 Polymerization of cis-DHDADA with BAB or BAE at different temperatures and at different times.

Polymerization of cis-DHDADA with $\mathrm{BAB}$ at $80^{\circ} \mathrm{C}$ in DMAc for $12 \mathrm{~h}$ yielded the soluble polyimide, with number-average and weightaverage molecular weights estimated at 23400 and 60300 , respectively. The polyimide was obtained even when polymerization was conducted at $60{ }^{\circ} \mathrm{C}$ for $24 \mathrm{~h}$. The polymerization at $60^{\circ} \mathrm{C}$ for $12 \mathrm{~h}$ yielded a polymer composed of both imide and amide acid units. Generally, the polymerization of dianhydrides with diamines forms poly(amic acid)s in solutions. Dehydrating imidation polymerization of the cisDHDADA with diamines, however, proceeded in a solution without catalysts even at $60^{\circ} \mathrm{C}$. Because of the flexibility of the bond angles 
around the arsenic center in the novel organoarsenic compound, conjugation stabilization may be the main driving force for the facile formation of the imide structure even at $60^{\circ} \mathrm{C}$ in solution. In addition, this is the first reported polyimide containing arsenic atoms in the main chains. An investigation of further details of the properties of the polymers is currently underway.

\section{ACKNOWLEDGEMENTS}

This work was supported by a Grant-in-Aid for Scientific Research (No. 20350054) from the Ministry of Education, Culture, Sports, Science and Technology, Government of Japan.

1 Manners, I. Polymers and the periodic table: recent developments in inorganic polymer science. Angew. Chem. Int. Ed. 35, 1603-1621 (1996).

2 Manners, I. Polymer science with transition metals and main group elements: towards functional, supramolecular inorganic polymeric materials. J. Polym. Sci. Part A: Polym. Chem. 40, 179-191 (2002).

3 Wright, V. A., Patrick, B. O., Schneider, C. \& Gates, D. P. Phosphorus copies of PPV: $\pi$-conjugated polymers and molecules composed of alternating phenylene and phosphaalkene moieties. J. Am. Chem. Soc. 128, 8836-8844 (2006).

4 Matsumi, N. \& Chujo, Y. $\partial$-Conjugated organoboron polymers via the vacant $p$-orbital of the boron atom. Polym. J. 40, 77-89 (2008).

5 Naka, K. Synthesis of polymers containing group 15 elements via bismetallation of acetylenic compounds. Polym. J. 40, 1031-1041 (2008).

6 Li, Z., Liu, J., Gao, Z., Yin, Z., Fan, L. \& Yang, S. Organo-soluble and transparent polyimides containing phenylphosphine oxide and trifluoromethyl moiety: synthesis and characterization. Eur. Polym. J. 45, 1139-1148 (2009).
7 Tagle, L. H., Terraza, C. A., Leiva, A. \& Valenzuela, P. Poly(amides) and poly(imides) containing silicon and germanium in the main chain: synthesis, characterization and thermal studies. J. Appl. Polym. Sci. 102, 2768-2776 (2006).

8 You, N.- H., Fukuzaki, N., Suzuki, Y., Nakamura, Y., Higashihara, T., Ando, S. \& Ueda, M. Synthesis of high-refractive index polyimide containing selenophene unit. J. Polym. Sci.: Part A: Polym. Chem. 47, 4428-4434 (2009).

9 Watson, K. A., Palmieri, F. L. \& Connell, J. W. Space environmentally stable polyimides and copolyimides derived from [2,4-Bis(3-aminophenoxy)phenyl]diphenylphosphine oxide. Macromolecules 35, 4968-4974 (2002).

10 Fukuzaki, N., Higashihara, T., Ando, S. \& Ueda, M. Synthesis and characterization of highly refractive polyimides derived from thiophene-containing aromatic diamines and aromatic dianhydrides. Macromolecules 43, 1836-1843 (2010).

11 Carison, B., Phelan, G. D., Kaminsky, W., Dalton, L., Jiang, X., Liu, S. \& Jen, A. K. Y. Divalent osmium complexes: synthesis, characterization, strong red phosphorescence, and electrophosphorescence. J. Am. Chem. Soc. 124, 14162 (2002).

12 Uberman, P.M., Lanteri, M.N. \& Mart, S.E. Highly efficient palladium-catalyzed arsination. Synthesis of a biphenyl arsine ligand and its application to obtain perfluoroalkylarsines. Organometallics 28, 6927-6934 (2009).

13 Nakahashi, A., Naka, K. \& Chujo, Y. 1,4-Dihydro-1,4-diarsinine: facial synthesis via non-volatile arsenic intermediates by radical reaction. Organometallics 26, 18271830 (2007).

14 Arita, M., Naka, K., Morisaki, Y., Nakahashi, A. \& Chujo, Y. Synthesis and characterization of stereoisomers of 1,4-dihydro-1,4-diarsinines. Organometallics 28, 6109-6113 (2009).

15 Higashi, T. ABSCOR. Program for Absorption Correction (Rigaku Corporation, Japan, 1995).

16 Beurskens, P. T., Beurskens, G., Bosman, W. P., de Gelder, R., Garcia-Granda, S., Gould, R. O., Israel, R. \& Smits, J. M. M. DIRDIF99.2 Program System (Crystallography Laboratory, University of Nijmegen, The Netherlands, 1999).

17 Sheldrick, G. M. SHELXL-97 (University of Göttingen, Göttingen, Germany, 1997).

18 Wakita, K. Yadokari-XG. Program for Crystal Structure Analysis 2000.

19 Burnett, M. N. \& Johnson, C. K. ORTEPIII Report ORNL-6895 (Oak Ridge National Laboratory, Tennessee, USA, 1996).

20 Akutsu, H., Ogasawara, M., Saburi, M., Kozawa, K. \& Uchida, T. Structure and characterization of 9,10-diethyl-9,10-diphospha-9,10-dihydroanthracene as an electron donor. Bull. Chem. Soc. Jpn. 69, 1223-1226 (1996). 